
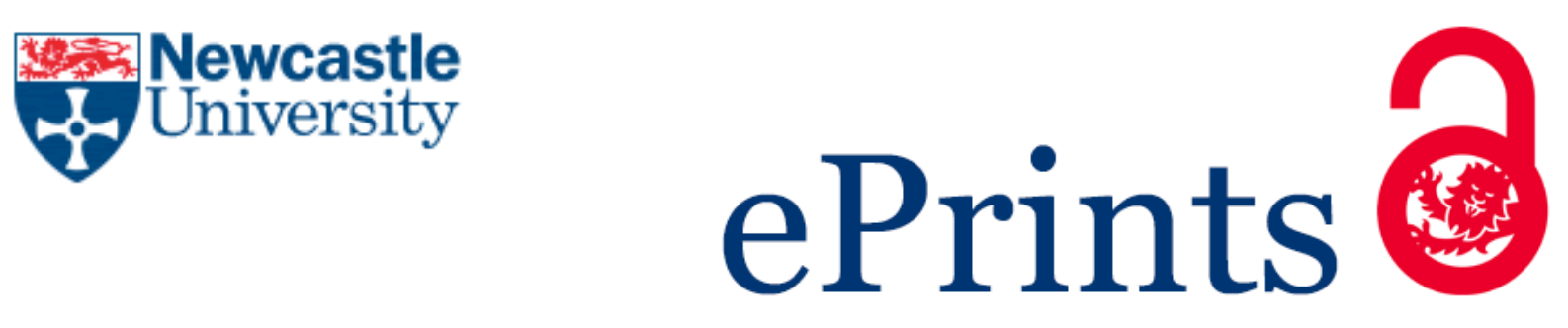

Bulley A, Pepper GV.

Cross-country relationships between life expectancy, intertemporal choice

and age at first birth.

Evolution and Human Behavior 2017,

https://doi.org/10.1016/j.evolhumbehav.2017.05.002

\title{
Copyright:
}

(C) 2017. This manuscript version is made available under the CC-BY-NC-ND 4.0 license

DOI link to article:

https://doi.org/10.1016/j.evolhumbehav.2017.05.002

Date deposited:

$09 / 05 / 2017$

Embargo release date:

04 May 2018

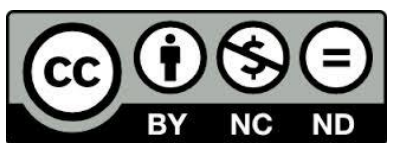

This work is licensed under a

Creative Commons Attribution-NonCommercial-NoDerivatives 4.0 International licence 
Cross-country relationships between life expectancy, intertemporal choice and age at first birth

\author{
Adam Bulley $^{1 *}$ and Gillian V. Pepper ${ }^{2 *}$
}

${ }^{1}$ Corresponding author. The University of Queensland, St. Lucia, Australia, QLD 4072.

Email: adam.bulley@uqconnect.edu.au

${ }^{2}$ Centre for Behaviour and Evolution, Newcastle University, Henry Wellcome Building,

Framlington Place, Newcastle Upon Tyne, UK NE2 4HH. Email: gillian.pepper@ncl.ac.uk

*The authors contributed equally to this work

Total submission word count: 5713 


\begin{abstract}
Humans, like other animals, typically discount the value of delayed rewards relative to those available in the present. From an evolutionary perspective, prioritising immediate rewards is a predictable response to high local mortality rates, as is an acceleration of reproductive scheduling. In a sample of 46 countries, we explored the cross-country relationships between average life expectancy, intertemporal choice, and women's age at first birth. We find that, across countries, lower life expectancy is associated with both a smaller percentage of people willing to wait for a larger but delayed reward, as well as a younger age at first birth. These results, which hold when controlling for region and economic pressures (GDP-per capita), dovetail with findings at the individual level to suggest that life expectancy is an important ecological predictor of both intertemporal and reproductive decision-making.
\end{abstract}

Keywords: Intertemporal choice, delay discounting, evolution, mortality, age at first birth, human behavioral ecology 


\section{Cross-country relationships between life expectancy, intertemporal choice and age at}

\section{first birth}

\section{Introduction}

Humans, like other animals, typically discount the subjective value of delayed rewards relative to those available in the present (Berns, Laibson, \& Loewenstein, 2007). Explanations for this delay discounting phenomenon tend to emphasize that the uncertainty of future rewards makes capitalising on immediate opportunities a beneficial strategy in many circumstances (Andreoni \& Sprenger, 2012; Daly \& Wilson, 2005; Stevens \& Stephens, 2010). Indeed, 'intertemporal choices' between immediate and delayed rewards are highly sensitive to context in humans (Lempert \& Phelps, 2015). One common prediction about the role of ecological context, grounded in evolutionary theorising, is that intertemporal decision-making should on average shift towards immediate rewards when local mortality rates are high (e.g. Daly \& Wilson, 2005; Frankenhuis, Panchanathan, \& Nettle, 2016; Hill, Jenkins, \& Farmer, 2008; Kruger \& Zimmerman, 2008). This is because a higher mortality risk equates to a lower likelihood of capitalising on delayed rewards due to the possibility of death. This is expected to take place both for an individual who may come to change their decision-making based on exposure to relevant information in their environment, but also at the group level whereby shared ecological factors like higher local mortality rates should produce on average steeper delay discounting.

Various lines of evidence support this proposition at the individual psychological level, including findings that exposure to natural disasters, violence or mortality cues is associated with a preference for immediate rewards over delayed ones (Lahav, Benzion, \& Shavit, 2011; Li et al., 2012; Pepper \& Nettle, 2013; Ramos, Victor, Seidl-de-Moura, \& Daly, 2013). Thus far, the evidence on this front comes from between- or within-participant analyses within the same country (e.g. Ramos et al., 2013), and analyses have tended to focus 
on specific cues of mortality risk, such as exposure to violence, rather than local mortality rates more generally. Here we therefore extend this work by asking whether variation in life expectancy across countries acts as an ecological predictor of the average intertemporal decision-making in those countries.

A similar logic applies in the domain of reproductive scheduling (Chisholm, 1993; Nettle, 2011; Wilson \& Daly, 1997). As local mortality risk increases, people are expected to reproduce earlier, and to produce more offspring throughout their reproductive careers (Charnov, 1991; Ellis, Figueredo, Brumbach, \& Schlomer, 2009; Stearns, 1992). The benefits of accelerated reproductive scheduling when mortality risk is high are thought to arise from both an increased chance of reproducing, and increased time available to care for offspring, before death. There is evidence that both within and between countries, women's average age at first birth is younger when mortality rates are higher (Low, Hazel, Parker, \& Welch, 2008). Local mortality risk indicators also predict total fertility, such that people in higher mortalityrisk conditions tend to have more children on average throughout the lifespan (Guégan, Thomas, Hochberg, de Meeus, \& Renaud, 2001; Zhang \& Zhang, 2005). We therefore sought to also replicate these previously reported relationships between life expectancy and age at first birth. Steeper temporal discounting has also been associated with having more sexual partners, an earlier age of first sexual activity, more relationship infidelity, greater odds of having a past or current pregnancy, and lower contraceptive use (Chesson et al., 2006; McCoul \& Haslam, 2001; Reimers, Maylor, Stewart, \& Chater, 2009). However it has thus far gone unexamined how average intertemporal decision-making patterns relate to reproductive scheduling patterns across different ecologies.

The current study therefore had two main aims. Firstly, we aimed to explore the relationship between life expectancy, and both intertemporal choice and age at first birth. Secondly, we aimed to explore the association between intertemporal choice and age at first 
birth. We hypothesized that, across countries, (i) lower average life expectancy would be associated with a lower percentage of people willing to wait for a larger later reward, (ii) lower average life expectancy would be associated with younger age at first birth, as found in prior studies, and (iii) a lower percentage of people willing to wait for a larger later reward would be associated with younger average age at first birth.

\section{Method}

\subsection{Measures}

2.1.1. Intertemporal choice. Intertemporal choice data were collected as a single binary choice item in the International Test of Risk Attitudes (INTRA) survey conducted by the University of Zurich and made publicly available in a recent publication (Wang, Rieger, \& Hens, 2016). Participants were asked to indicate whether they would prefer: (A) a payment of $\$ 3400$ this month; or (B) a payment of $\$ 3800$ next month (from Frederick, 2005). Participants were university students (mostly in the departments of economics, finance, and business administration) and the monetary amounts in the choice question were adjusted according to the Purchasing Power Parity and monthly income and expenses of the students in each country. The sample contained intertemporal choice data from 6901 participants from 53 countries. These responses were used to calculate the percentage of respondents from each country who chose the delayed but larger reward. More details about the methodology of the INTRA survey are available from Wang et al., (2016) and Rieger et al., (2015).

\subsubsection{GDP-PC, life expectancy, age at first birth and region. Data on gross} domestic product per capita (GDP-PC) and life expectancy for 52 of the 53 countries for which intertemporal choice data were available from the World Bank open data bank available online (The World Bank, 2016). INTRA survey data on percentage of people willing to wait were available for Taiwan, but GDP-PC, life expectancy and age at first birth 
data were not. Therefore, Taiwan was not included in our analyses. Data on age at first birth were available from the CIA World Fact Book online (CIA, 2016). Age at first birth data were not available for Argentina, Chile, China, Lebanon, Malaysia, or Vietnam, leaving complete data for 46 countries. Because the INTRA data on intertemporal choice were collected over a number of years (between 2007-2012), GDP-PC and life expectancy data were averaged over the years during which the intertemporal choice data were collected in each country (details of the years during which data were collected were provided by Wang et al. in correspondence, and can be seen in the data provided as an electronic supplement). The available data on age at first birth lacked the same level of temporal specificity, and were instead collected at various time-points ranging from 2006 to 2012.

GDP-PC was measured in USD, and is defined by the World Bank as "gross domestic product divided by midyear population". The World Bank defines GDP as "the sum of gross value added by all resident producers in the economy plus any product taxes and minus any subsidies not included in the value of the products. It is calculated without making deductions for depreciation of fabricated assets or for depletion and degradation of natural resources." Life expectancy, another World Bank indicator, is defined as: "the number of years a newborn infant would live if prevailing patterns of mortality at the time of its birth were to stay the same throughout its life". Age at first birth, as defined by the CIA world fact book, represents: "the mother's mean age at first birth" for a given country. Region classifications were assigned as per the World Bank’s “Country and Lending Groups” classifications, available online. 


\subsection{Data analysis}

Hypotheses, measures, and our analytical plan were pre-registered with the Open Science Framework ${ }^{1}$. All statistical analyses were performed in R studio (R Core Team, 2008). We created a series of linear mixed models to address each hypothesis, with a random intercept of 'region' to control for the potential non-independence of the sample countries due to shared features such as climate and cultural histories, using lme4 (Bates, Maechler, \& Walker, 2015). The sample sizes obtained in the INTRA survey varied by country (range = 38-540, Wang et al., 2016). Analyses were therefore weighted for the sample size of the intertemporal choice data. All predictors were standardised in order to deal with the scale differences between GDP-PC and the other predictor variables. Plots were created with ggplot2 (Wickham, 2009) and ggrepel (Slowikowski, 2016). We also used the dplyr (Wickham, 2016) and psych (Revelle, 2014) packages to organise the data and generate descriptive statistics. The $\mathrm{R}$ script used for analysis is available as an electronic supplement to this paper, as is the dataset and an information sheet about the included variables. As part of our electronic supplement, we have also created maps to visualise the cross-country variation in life expectancy (available online, here), intertemporal choice (available here), and age at first birth (available here).

\footnotetext{
${ }^{1}$ Changes to the pre-registered analytical plan were as follows: Firstly, due to a serious lack of adherence to statistical assumptions, models with the 'fertility' variable were removed from our final analyses. Subsequently, we generated new hypotheses about age at first birth and included analyses to test these hypotheses after failing to fit adequate models with the fertility data. Finally, we removed the planned mediation analysis due to concerns about testing for individual-level psychological mechanisms using country-level data (the ecological fallacy; see Kuppens \& Pollet, 2014), and employed linear mixed models with a random effect of region instead of standard linear models.
} 


\section{Results}

\subsection{Descriptive statistics}

Descriptive statistics for the percentage of people willing to wait, GDP-PC, life expectancy and age at first birth are available in Table 1. As might be expected, countries with a higher GDP-PC tended to have longer life expectancies $\left(X^{2}(1)=33.33, p<0.001, \beta=\right.$ 3.13, s.e. $=0.45)$.

Table 1. Descriptive statistics for the main study variables

\begin{tabular}{lllllll}
\hline & Mean & SD & Min & Max & Range & $\mathrm{n}$ \\
\hline Percentage willing to wait & 0.63 & 0.18 & 0.08 & 0.89 & 0.81 & 52 \\
GDP-PC & 27852.22 & 24939.17 & 657.73 & 113239.56 & 112581.83 & 52 \\
Age at first birth & 26.84 & 3.42 & 19.4 & 31.2 & 11.8 & 46 \\
Life expectancy & 75.89 & 7.02 & 49.85 & 82.51 & 32.66 & 52 \\
\hline
\end{tabular}

\subsection{Relationship between life expectancy and intertemporal choice}

We conducted a linear mixed effects analysis of the relationship between life expectancy and intertemporal choice, controlling for GDP-PC and a random effect of geographic region. As fixed effects, we entered GDP-PC and life expectancy, and as a random effect we included a random intercept of region. We obtained $p$-values by running likelihood ratio tests, using the drop1 function (Chambers, 1992) to compare the fit of the full model with those of models with each predictor removed. Results revealed a relationship between life expectancy and intertemporal choice $\left(X^{2}(1)=9.88, p<0.01\right)$, such that a higher life expectancy was associated with a higher percentage of people willing to wait for the larger, later reward on average $(\beta=0.09$, s.e. $=0.03$, Figure 1 , Table 2$)$. Thus, people in countries with a shorter average life expectancy tended to be less willing on average to wait for the delayed reward. Note that results of a similar model excluding life expectancy 
revealed a relationship between GDP-PC and intertemporal choice $\left(X^{2}(1)=17.99, p<\right.$ 0.001), such that a greater GDP-PC was associated with a higher percentage of people willing to wait for the larger, later reward on average $(\beta=0.1$, s.e. $=0.02)$. However, this effect of GDP-PC on intertemporal choice was attenuated when life expectancy is included in the model (Table 2).

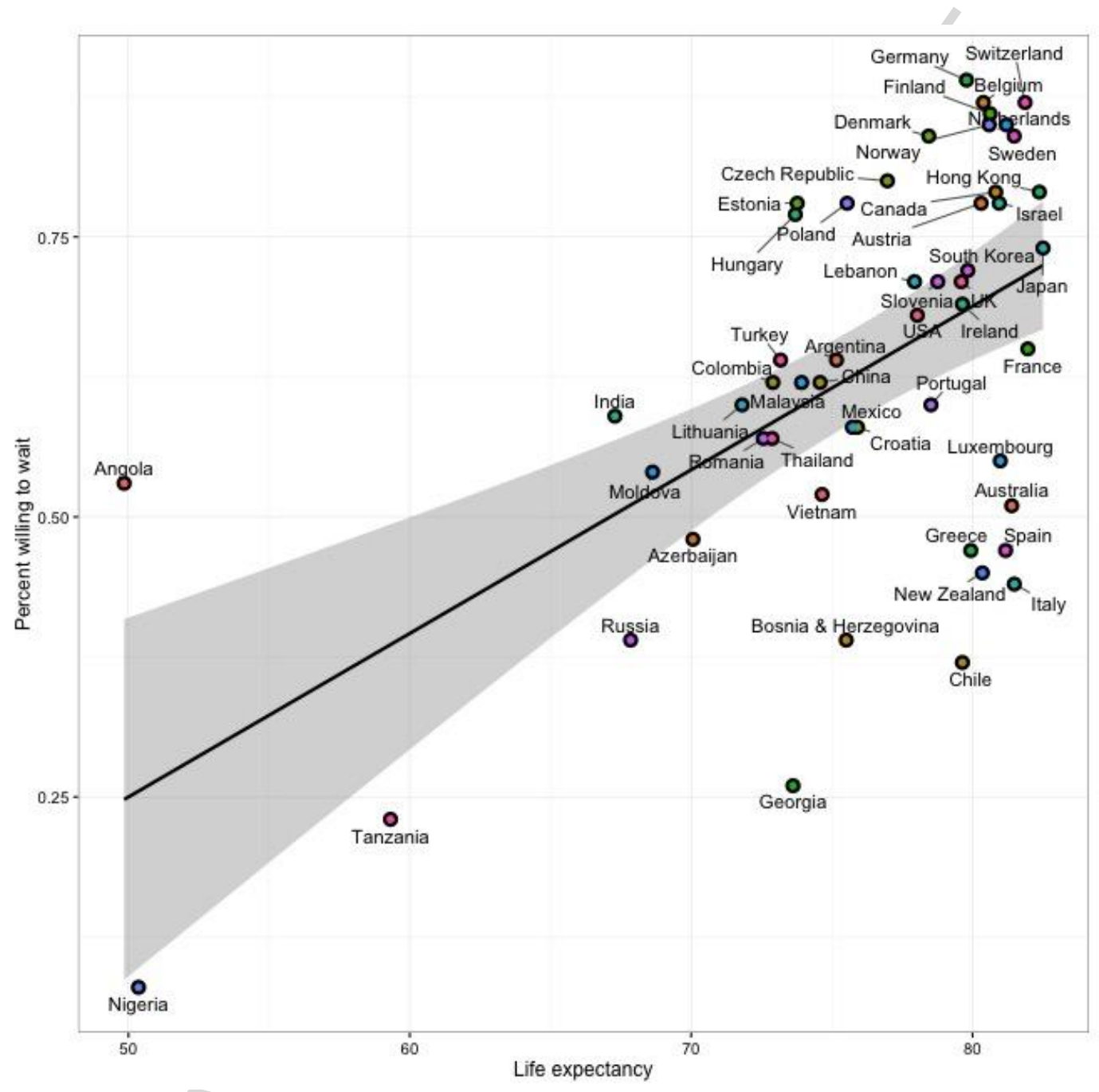

Figure 1. Relationship between average life expectancy across countries and the percentage of people willing to wait for a larger later reward: $r=0.57, p<0.001$ 
Table 2. Results of the full mixed effects model predicting intertemporal choice with GDPPC and life expectancy, with a random effect of region. P-values derived from LRTs.

\begin{tabular}{lrrr}
\hline & \multicolumn{2}{c}{ Intertemporal choice } \\
\hline Fixed effects & $\boldsymbol{\beta}$ & SE & p \\
\hline GDP-PC & 0.05 & 0.02 & 0.06 \\
Life expectancy & 0.09 & 0.03 & \\
& & & \\
Random effects & Variance & SD & \\
\hline Region (intercept) & 0.00 & 0.00 & \\
Residual & 2.09 & 1.45 & \\
& & & \\
\hline AIC & -46.9 & & \\
N (countries) & 52 & & \\
\hline
\end{tabular}

\subsection{Relationships between life expectancy, intertemporal choice, and age at first birth}

We conducted linear mixed effects analyses of the relationships between life expectancy, intertemporal choice and age at first birth, controlling for GDP-PC and a random effect of geographic region. Again, we compared models with likelihood ratio tests using the drop1 function (Chambers, 1992).

Results revealed a relationship between life expectancy and age at first birth $\left(X^{2}(1)=\right.$ 16.77, $\mathrm{p}<0.01$, Table 2) after controlling for GDP-PC, intertemporal choice, and region, such that a lower life expectancy was associated with a younger age at first birth, in line with prior findings (e.g. Low et al., 2008; $\beta=2.32$, s.e. $=0.52$, Figure 2 ). We found no relationship between intertemporal choice and age at first birth after controlling for GDP-PC, life expectancy and region $\left(X^{2}(1)=0.34, p=0.56\right.$, Table 3), even though this relationship was seen before controlling for these variables $(r=0.50, p<0.001$, Figure 3$)$, and was a significant predictor in a model controlling for GDP-PC and region, but not life expectancy $\left(\mathrm{X}^{2}(1)=4.11, \mathrm{p}=0.04\right)$. 
Table 3. Results of the full mixed effects model predicting age at first birth with intertemporal choice, GDP-PC and life expectancy, with a random effect of region.

\section{Age at first birth}

\begin{tabular}{lrrr}
\hline Fixed effects & $\boldsymbol{\beta}$ & SE & p \\
\hline GDP-PC & 0.61 & 0.35 & 0.10 \\
Life expectancy & 2.32 & 0.52 & $<0.001$ \\
Intertemporal choice & 0.19 & 0.33 & 0.56
\end{tabular}

\begin{tabular}{lrr} 
Random effects & Variance & SD \\
\hline Region (intercept) & 2.77 & 1.67 \\
Residual & 297.53 & 17.25
\end{tabular}

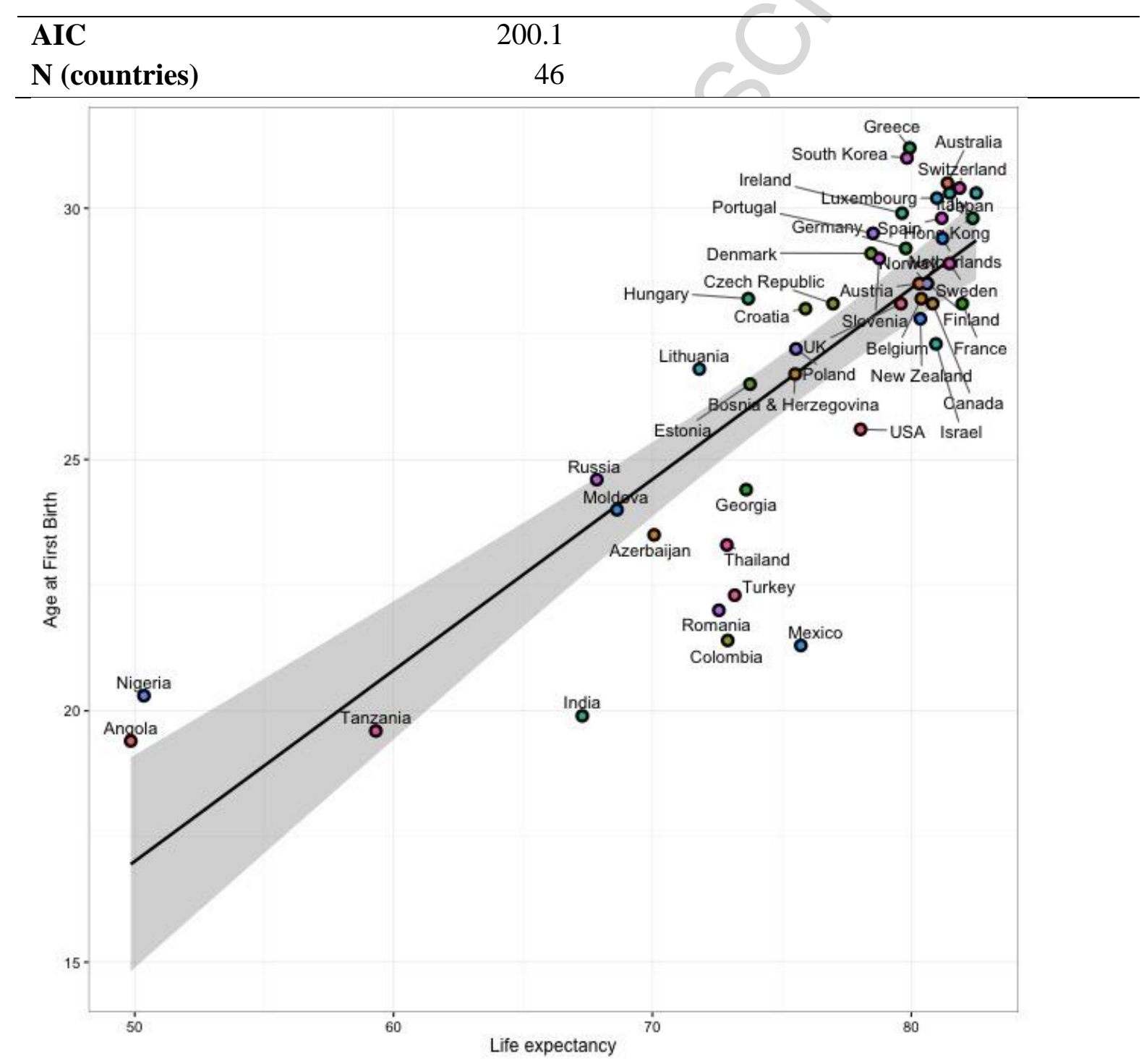

Figure 2. Relationship between average life expectancy across countries and average age at first birth: $\mathrm{r}=0.83, \mathrm{p}<0.001$ 


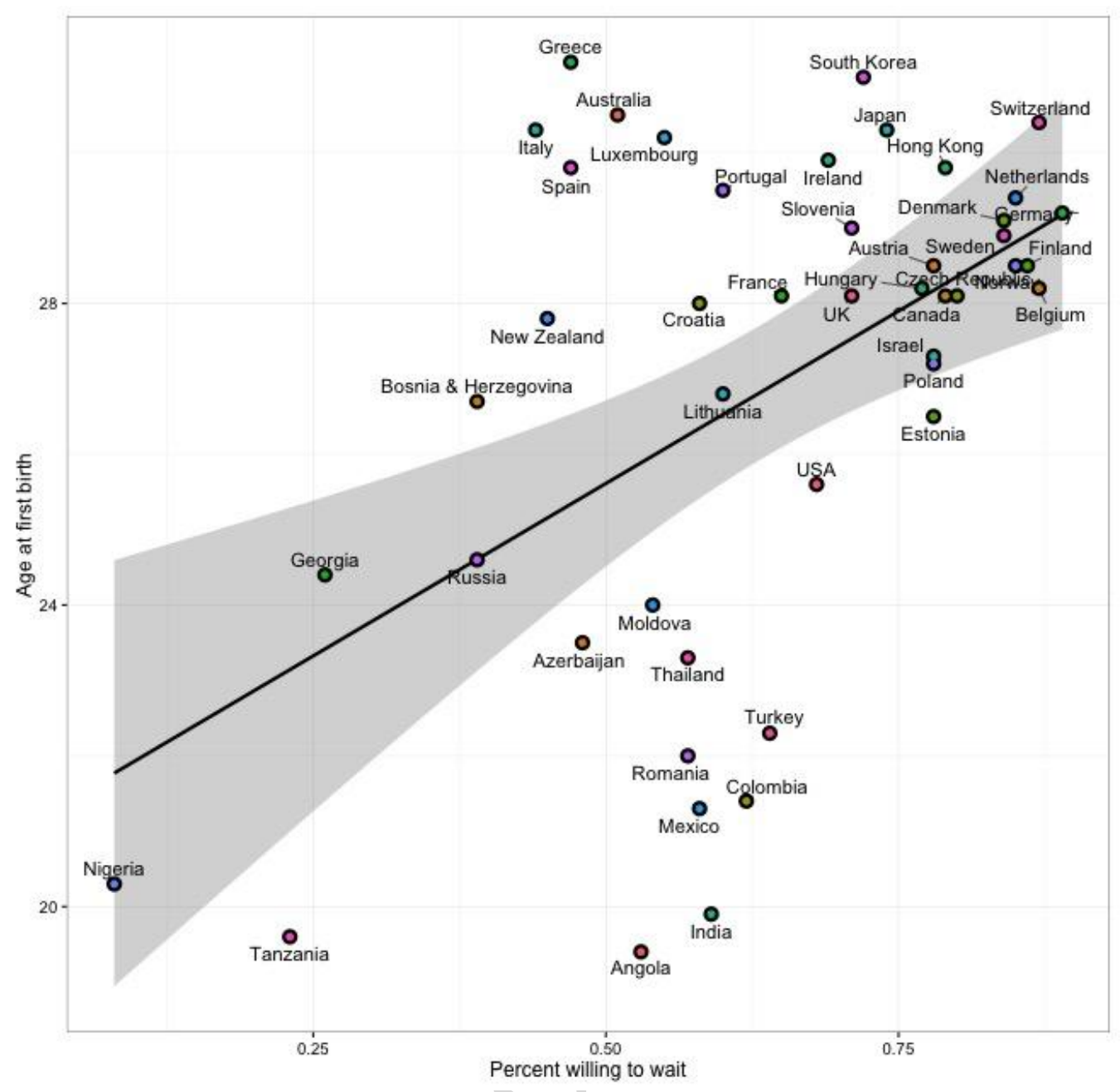

Figure 3. Relationship between the percentage of people willing to wait for a larger later reward and average age at first birth across countries: $\mathrm{r}=0.50, \mathrm{p}<0.001$ 


\section{Discussion}

We tested associations between life expectancy, intertemporal choice, and age at first birth in a cross-sectional sample of 46 countries. We predicted that, across countries: (i) lower life expectancy would be associated with fewer people willing to wait for a larger later reward; (ii) in line with prior findings, lower life expectancy would be associated with younger age at first birth; and (iii) a lower percentage of people willing to wait for a larger later reward would be associated with younger age at first birth. Results support these hypotheses, with the relationships remaining significant even after controlling for region and general wealth (GDP-PC). However, the percentage of people willing to wait was no longer a predictor of age at first birth when life expectancy was included in the model. Thus, hypothesis (iii) is likely only supported because life expectancy is associated with both willingness to wait, and with age at first birth, rather than because willingness to wait affects age at first birth directly.

This is the first study, to our knowledge, to examine the cross-country level association between life expectancy and intertemporal choice. The results dovetail with findings at the individual level, which suggest that people whose experiences seem indicative of a limited life expectancy tend to discount future rewards more steeply (e.g. Lahav, Benzion, \& Shavit, 2011; Li et al., 2012; Pepper \& Nettle, 2013). However, while these similar findings at the individual level are suggestive of the possibility that people might adjust their intertemporal choice to accord with local mortality rates, the current results also reveal life expectancy itself to be an important ecological predictor of intertemporal choice on aggregate. Further studies will be needed at the individual level to determine if individual life expectancy predicts intertemporal decision-making in a similar way. Because intertemporal choice is associated with health-related behaviour and outcomes (Story, Vlaev, Seymour, Darzi, \& Dolan, 2014), as well as people's beliefs (Shenhav, Rand, \& Greene, 
2017) and economic behaviours (Falk et al., 2015), identifying ecological variables that predict aggregate intertemporal decision-making may be useful to public health specialists and other professionals aiming to improve outcomes predicted by intertemporal choice. For example, developing a reliable account of the factors which predict health investment by accounting for various ecological predictors would enable those creating health campaigns to target those areas where potentially deleterious decision-making patterns are most likely to emerge.

Given the cross-sectional nature of our data, we cannot confirm that the associations we have reported are causal. Neither can the direction of any causal association be discerned. This leaves open at least two possible explanations for the observed association between life expectancy and intertemporal choice. Firstly, it is possible that ecological conditions giving rise to lower life expectancy lead to a greater preference for immediate rewards. In line with a number of theoretical perspectives from human behavioural ecology and evolutionary psychology, people may shift their intertemporal decision-making towards immediate rewards in countries with higher mortality risk (e.g. Daly \& Wilson, 2005). Our results do not speak to the phylogenetic, developmental or psychological mechanisms that might underpin this shift, though recent works have highlighted some plausible (and potentially intersecting) proximate accounts including developmental plasticity (Frankenhuis et al., 2016), implicit adjustment on the basis of external cues (Pepper \& Nettle, 2013) and explicit mental reasoning or planning (Bulley, Henry, \& Suddendorf, 2016).

Another, non-mutually exclusive explanation for the relationship between life expectancy and intertemporal choice is that a greater preference for immediate rewards in intertemporal choice leads to lower life expectancy by decreasing efforts to protect future health. Increased delay discounting has been associated with a host of poorer health behaviours and outcomes (for a review see Story, Vlaev, Seymour, Darzi, \& Dolan, 2014). If 
the relationship observed in this study runs in both of the aforementioned directions, then we can speculate about the feedback loops that might be generated. Specifically, if cues signifying unavoidable mortality risk lead to increased temporal discounting and decreased health-promoting behaviour, thereby lowering life expectancy, then a feedback loop may be initiated: with lower life expectancy causing greater temporal discounting and a disinvestment in future health, which in its turn reiterates the cycle (Griskevicius, Tybur, Delton, \& Robertson, 2011; Nettle, 2010b; Pepper \& Nettle, 2013, 2014, 2017).

The current results also replicate a previously-observed relationship between life expectancy and age at first birth, such that lower life expectancy was associated with a younger age at first birth. Similar findings have previously been reported both between and within countries (Bulled \& Sosis, 2010; Low et al., 2008; Low, Parker, Hazel, \& Welch, 2013; Nettle, 2010a; Quinlan, 2010; Wilson \& Daly, 1997). The prevailing explanation for this association in evolutionary terms is that as local mortality rates increase, people adopt accelerated reproductive scheduling in order to maximise their potential investment in offspring. An earlier age at first birth is predicted to be adaptive when life expectancy is lower because this increases both the chances of reproducing and the length of time available to care for offspring before death (Chisholm, 1993; see Harvey \& Zammuto, 1985 for an analogous cross-species pattern). Investing resources in offspring is ostensibly a more adaptive strategy when extrinsic (uncontrollable) mortality risks are low. For more on the relevant trade-offs inherent to reproductive scheduling and decision-making, see (Hill, Ross, \& Low, 1997; Low, 2015; Wilson \& Daly, 1997).

Our results also showed a correlation between intertemporal choice and age at first birth, such that a higher percentage of people willing to wait for a larger later reward was associated with a lower age at first birth across countries. It is likely that this relationship manifests because both intertemporal choice and age at first birth are associated with life 
expectancy. Indeed, intertemporal choice was no longer a significant predictor of age at first birth after controlling for life expectancy, suggesting that decision-making in financial and reproductive domains might be associated via different mechanisms.

Although we included GDP-PC in our analyses primarily as a control variable, it is interesting to note that the effect of GDP-PC on intertemporal choice is attenuated when life expectancy is added to the model (Table 2). This suggests that a portion of the effect of GDPPC on intertemporal choice may be accounted for by the fact that higher GDP-PC countries tend to have longer life expectancies. It is often assumed that the drivers of intertemporal choice are more economic or endogenous than ecological. However, a meaningful portion of the effect of economic variables such as wealth (at either individual or national level) on intertemporal choice may be exerted indirectly via the effects of wealth on ecological factors such as life expectancy.

There are a number of limitations to the current study that should be noted. Firstly, although there have been similar findings at the individual level, as discussed above, (e.g. Griskevicius, Delton, Robertson, \& Tybur, 2011; Griskevicius, Tybur, et al., 2011; Pepper \& Nettle, 2013; Quinlan, 2010; Rodgers, John, \& Coleman, 2005), the present analyses utilise aggregated cross-country level data, making any interpretations thereof prone to the ecological fallacy (Kuppens \& Pollet, 2014; Robinson, 1950). For this reason, we must be cautious of interpreting the results as if they refer to individual level processes, and instead recognise the utility of the revealed cross-country level relationships in their own right. It will be important for future research to probe these associations, and to extend them at the individual level, with experimental studies better placed to discern causality in these domains (e.g. McAllister, Pepper, Virgo, \& Coall, 2016).

Secondly, the economic characteristics of the countries in our sample were relatively restricted. Specifically, the sample contained very few countries with lower GDP-PCs and 
life expectancies. Thus, while cross-country data on intertemporal preferences are difficult to collect, future studies should focus on countries at the lower end of the GDP-PC and life expectancy continua. Thirdly, the intertemporal choice data from within each country were not nationally representative, being instead comprised of college student samples (see Wang et al., 2016 for details and additional consideration of the limitations of this data). These samples most likely represented populations that were relatively more educated and affluent than the country average. Given that such affluence and education have been linked to increased patience (Haushofer \& Fehr, 2014), the data may underestimate the true levels of discounting in each country. With that said, the samples are biased in a similar manner across countries, meaning that the differences between countries are still informative.

Finally, the intertemporal choice measure employed in the current study simply represented the percentage of people in the sample from each country that indicated they were willing to wait for a larger later reward over an immediately available one. The survey item by which this data was collected is a single-shot intertemporal choice question, confirmed by subsequent questions designed to measure the discount rate over longer periods (1 year, and 10 years). The measure is thus unlikely to provide the same precision as a full intertemporal choice questionnaire such as the Kirby discounting survey, which enables the calculation of a temporal discounting index such as 'area under the curve' (Kirby, Petry, \& Bickel, 1999). Nonetheless, one-shot intertemporal choice questions have been shown to have significant predictive power in relevant domains such as age of first sexual activity, and appear to give similar results to more traditional adjusting-amount procedures for fitting discounting functions (Reimers et al., 2009).

This study provides the first examination, to our knowledge, of a cross-country level association between life expectancy and intertemporal choice. Across 52 countries, we find that lower life expectancy is associated with a lower percentage of people willing to wait for 
a larger, later reward. In line with previous studies, our results also show that a lower average life expectancy is associated with an earlier average age at first birth. Finally, we find that a lower percentage of people willing to wait for a delayed reward is associated with a younger average age at first birth across a subsample of 46 countries. These relationships all held true after controlling for GDP-PC and region. However, the relationship between intertemporal choice and age at first birth was not significant when controlling for life expectancy indicating that, although life expectancy is associated with both intertemporal choice and age at first birth, intertemporal choice may not influence age at first birth directly.

Our results dovetail with a body of research at the individual and cross-country level that suggests people adjust their intertemporal and reproductive scheduling decisions on the basis of relevant environmental variables, including local mortality risk. The results are also in line with findings that accentuated temporal discounting is associated with a host of poorer health behaviours and outcomes, which may result in a reduced life expectancy. They suggest that life expectancy is an important predictor of intertemporal and reproductive decisionmaking at the aggregate level, making it worthy of further investigation.

\section{Acknowledgements}

We thank James M. Sherlock, Sean C. Murphy and Thomas Suddendorf for their helpful comments on an earlier version of this paper. We also thank Bobbi S. Low, Quentin Atkinson and one anonymous reviewer for their helpful comments.

Funding: This research did not receive any specific grant from funding agencies in the public, commercial, or not-for-profit sectors. 


\section{References}

Andreoni, J., \& Sprenger, C. (2012). Risk Preferences Are Not Time Preferences. American Economic Review, 102(7), 3357-3376. http://doi.org/10.1257/aer.102.7.3357

Bates, D., Maechler, B. B., \& Walker, S. (2015). Fitting Linear Mixed-Effects Models Using lme4. Journal of Statistical Software, 67(1), 1-48.

Berns, G. S., Laibson, D., \& Loewenstein, G. (2007). Intertemporal choice - toward an integrative framework. Trends in Cognitive Sciences, 11(11), 482-488. http://doi.org/10.1016/j.tics.2007.08.011

Bulled, N. L., \& Sosis, R. (2010). Examining the Relationship between Life Expectancy, Reproduction, and Educational Attainment. Human Nature, 21(3), 269-289. http://doi.org/10.1007/s12110-010-9092-2

Bulley, A., Henry, J., \& Suddendorf, T. (2016). Prospection and the present moment: The role of episodic foresight in intertemporal choices between immediate and delayed rewards. Review of General Psychology, 20(1), 29-47. http://doi.org/http://dx.doi.org/10.1037/gpr0000061

Chambers, J. M. (1992). Linear models. In JM Chambers and TJ Hastie (Ed.), Statistical Models in S. JOUR, Wadsworth \& Brooks/Cole.

Charnov, E. L. (1991). Evolution of life-history variation among female mammals. Proceedings of the National Academy of Sciences of the United States of America, 88(4), 1134-1137. http://doi.org/Doi 10.1073/Pnas.88.4.1134

Chesson, H. W., Leichliter, J. S., Zimet, G. D., Rosenthal, S. L., Bernstein, D. I., \& Fife, K. H. (2006). Discount rates and risky sexual behaviors among teenagers and young adults. Journal of Risk and Uncertainty, 32(3), 217-230. http://doi.org/10.1007/s11166-0069520-1

Chisholm, J. S. (1993). Death , Hope, and Sex: Life-History Theory and the Development of Reproductive Strategies [and. Current Anthropology, 34(1), 1-24.

Daly, M., \& Wilson, M. (2005). Carpe Diem: Adaptation and Devaluing the Future. The Quarterly Review of Biology, 80(1), 55-60. http://doi.org/10.1086/521238

Ellis, B. J., Figueredo, A. J., Brumbach, B. H., \& Schlomer, G. L. (2009). Fundamental dimensions of environmental risk: The impact of harsh versus unpredictable environments on the evolution and development of life history strategies. Human Nature (Vol. 20). http://doi.org/10.1007/s12110-009-9063-7

Falk, A., Becker, A., Dohmen, T., Enke, B., Huffman, D., \& Sunde, U. (2015). The Nature and Predictive Power of Preferences: Global Evidence. Mimeo, (9504).

Frankenhuis, W. E., Panchanathan, K., \& Nettle, D. (2016). Cognition in harsh and unpredictable environments. Current Opinion in Psychology, 7, 76-80. http://doi.org/10.1016/j.copsyc.2015.08.011

Frederick, S. (2005). Cognitive Reflection and Decision Making. Journal of Economic Perspectives, 19(4), 25-42. http://doi.org/10.1257/089533005775196732

Griskevicius, V., Delton, A. W., Robertson, T. E., \& Tybur, J. M. (2011). Environment Contingency in Life History Strategies: The Influence of Mortality and Socioeconomic Status on Reproductive Timing. Journal of Personality and Social Psychology, 100(6), 
1015-26. http://doi.org/10.1037/a0022403

Griskevicius, V., Tybur, J. M., Delton, A. W., \& Robertson, T. E. (2011). The influence of mortality and socioeconomic status on risk and delayed rewards: a life history theory approach. Journal of Personality and Social Psychology, 100(6), 1015. Journal Article.

Guégan, J. F., Thomas, F., Hochberg, M. E., de Meeus, T., \& Renaud, F. (2001). Disease diversity and human fertility. Evolution, 55(7), 1308-1314. http://doi.org/10.2307/2680327

Harvey, P. H., \& Zammuto, R. M. (1985). Patterns of mortality and age at first reproduction in natural populations of mammals. Nature, 315(6017), 319-320. http://doi.org/10.1038/315319a0

Haushofer, J., \& Fehr, E. (2014). On the psychology of poverty. Science, 344(6186), 862-7. http://doi.org/10.1126/science.1232491

Hill, E. M., Jenkins, J., \& Farmer, L. (2008). Family unpredictability, future discounting, and risk taking. The Journal of Socio-Economics, 37(4), 1381-1396. Journal Article.

Hill, E. M., Ross, L. T., \& Low, B. S. (1997). The role of future unpredictability in human risk-taking. Human Nature, 8(4), 287-325. http://doi.org/10.1007/BF02913037

Kirby, K. N., Petry, N. M., \& Bickel, W. K. (1999). Heroin addicts have higher discount rates for delayed rewards than non-drug-using controls. Journal of Experimental Psychology. General, 128(1), 78-87. http://doi.org/10.1037/0096-3445.128.1.78

Kruger, D. J., \& Zimmerman, M. a. (2008). Time Perspective as a Mechanism for Functional Developmental Adaptation. Journal of Social, Evolutionary, and Cultural Psychology, 2(1), 1-22. http://doi.org/10.1037/h0099336

Kuppens, T., \& Pollet, T. V. (2014). Mind the level: Problems with two recent nation-level analyses in psychology. Frontiers in Psychology, 5(SEP), 1-4. http://doi.org/10.3389/fpsyg.2014.01110

Lahav, E., Benzion, U., \& Shavit, T. (2011). The effect of military service on soldiers' time preference-Evidence from Israel. Judgment and Decision Making, 6(2), 130-138. Journal Article.

Lempert, K. M., \& Phelps, E. a. (2015). The Malleability of Intertemporal Choice. Trends in Cognitive Sciences, xx, 1-11. http://doi.org/10.1016/j.tics.2015.09.005

Li, J. Z., Gui, D. Y., Feng, C. L., Wang, W. Z., Du, B. Q., Gan, T., \& Luo, Y. J. (2012). Victims' time discounting 2.5 years after the Wenchuan earthquake: An ERP study. PLoS ONE, 7(7), 1-8. http://doi.org/10.1371/journal.pone.0040316

Low, B. S. (2015). Why sex matters: A Darwinian look at human behavior. Revised Edition. BOOK, Princeton University Press.

Low, B. S., Hazel, A., Parker, N., \& Welch, K. B. (2008). Influences on Women's Reproductive Lives Unexpected Ecological Underpinnings. Cross-Cultural Research, 42(3), 201-219.

Low, B. S., Parker, N., Hazel, A., \& Welch, K. B. (2013). Life Expectancy, Fertility, and Women's Lives: A Life-History Perspective. Cross-Cultural Research, 47(2), 198-225. http://doi.org/10.1177/1069397112471807

McAllister, L. S., Pepper, G. V., Virgo, S., \& Coall, D. A. (2016). The evolved psychological 
mechanisms of fertility motivation: hunting for causation in a sea of correlation. Phil. Trans. R. Soc. B, 371(1692), 20150151. http://doi.org/10.1098/rstb.2015.0151

McCoul, M. D., \& Haslam, N. (2001). Predicting high risk sexual behaviour in heterosexual and homosexual men: The roles of impulsivity and sensation seeking. Personality and Individual Differences, 31(8), 1303-1310. http://doi.org/10.1016/S0191-8869(00)002221

Nettle, D. (2010a). Dying young and living fast: Variation in life history across English neighborhoods. Behavioral Ecology, 21(2), 387-395.

http://doi.org/10.1093/beheco/arp202

Nettle, D. (2010b). Why are there social gradients in preventative health behavior? A perspective from behavioral ecology. PloS One, 5(10), e13371. http://doi.org/10.1371/journal.pone.0013371

Nettle, D. (2011). Flexibility in reproductive timing in human females: integrating ultimate and proximate explanations. Philosophical Transactions of the Royal Society of London. Series B, Biological Sciences, 366(1563), 357-65. http://doi.org/10.1098/rstb.2010.0073

Pepper, G. V., \& Nettle, D. (2013). Death and the time of your life: Experiences of close bereavement are associated with steeper financial future discounting and earlier reproduction. Evolution and Human Behavior, 34(6), 433-439. Journal Article. http://doi.org/10.1016/j.evolhumbehav.2013.08.004

Pepper, G. V., \& Nettle, D. (2014). Socioeconomic Disparities in Health Behaviour: An Evolutionary Perspective, 225-243. http://doi.org/10.1007/978-1-4939-0280-4

Pepper, G. V., \& Nettle, D. (2017). The Behavioural Constellation of Deprivation: Causes and Consequences. Behavioral and Brain Sciences.

Quinlan, R. J. (2010). Extrinsic mortality effects on reproductive strategies in a Caribbean community. Human Nature, 21(2), 124-139. http://doi.org/10.1007/s12110-010-9085-1

$\mathrm{R}$ Core Team. (2008). $R$ : A language and environment for statistical computing. $R$ Foundation for Statistical Computing (Vol. 739). Vienna, Austria. http://doi.org/10.1007/978-3-540-74686-7

Ramos, D., Victor, T., Seidl-de-Moura, M. L., \& Daly, M. (2013). Future Discounting by Slum-Dwelling Youth Versus University Students in Rio de Janeiro. Journal of Research on Adolescence, 23(1), 95-102. http://doi.org/10.1111/j.15327795.2012.00796.x

Reimers, S., Maylor, E. a., Stewart, N., \& Chater, N. (2009). Associations between a one-shot delay discounting measure and age, income, education and real-world impulsive behavior. Personality and Individual Differences, 47(8), 973-978. http://doi.org/10.1016/j.paid.2009.07.026

Revelle, W. (2014). psych: Procedures for psychological, psychometric, and personality research. Northwestern University, Evanston, Illinois, 165. JOUR.

Rieger, M. O., Wang, M., \& Hens, T. (2015). Risk Preferences Around the World Risk Preferences Around the World. Management Science, 61(3), 637-648.

Robinson, W. S. (1950). Ecological correlations and the behavior of individuals. American Sociological Review, 15(3), 351-357. http://doi.org/10.1093/ije/dyr082 
Rodgers, J. L. E. E., John, C. A. S. T., \& Coleman, R. (2005). Did Fertility Go Up After the Oklahoma City Bombing? an Analysis of Births in Metropolitan Counties in Oklahoma, 1990-1999. Demography, 42(4), 675-692.

Shenhav, A., Rand, D. G., \& Greene, J. D. (2017). The relationship between intertemporal choice and following the path of least resistance across choices, preferences, and beliefs. Judgment and Decision Making, 12(1), 1-18. http://doi.org/10.2139/ssrn.2724547

Slowikowski. (2016). ggrepel: Repulsive Text and Label Geoms for "ggplot2." Retrieved from http://cran.r-project.org/package=ggrepel

Stearns, S. C. (1992). The evolution of life histories (Vol. 249). BOOK, Oxford University Press Oxford.

Stevens, J. R., \& Stephens, D. W. (2010). The adaptive nature of impulsivity. Impulsivity The Behavioral and Neurological Science of Discounting, 387, 361-388. Retrieved from http://digitalcommons.unl.edu/psychfacpub/519/

Story, G., Vlaev, I., Seymour, B., Darzi, A., \& Dolan, R. (2014). Does temporal discounting explain unhealthy behavior? A systematic review and reinforcement learning perspective. Front Behav Neurosci, 8. Journal Article. http://doi.org/10.3389/fnbeh.2014.00076

The World Bank. (2016). World Bank Open Data. Retrieved from http://data.worldbank.org/

Wang, M., Rieger, M. O., \& Hens, T. (2016). How time preferences differ: Evidence from 53 countries. Journal of Economic Psychology, 52, 115-135. http://doi.org/10.1016/j.joep.2015.12.001

Wickham, H. (2009). ggplot2: Elegant Graphics for Data Analysis. Springer-Verlag New York.

Wickham, H. (2016). dplyr: A Grammar of Data, RStudio. https://github.com/tidyverse/dplyr.

Wilson, M., \& Daly, M. (1997). Life expectancy, economic inequality, homicide, and reproductive timing in Chicago neighbourhoods. BMJ : British Medical Journal, 314(7089), 1271-1274. Journal Article. Retrieved from http://www.ncbi.nlm.nih.gov/pmc/articles/PMC2126620/

Zhang, J., \& Zhang, J. (2005). The effect of life expectancy on fertility, saving, schooling and economic growth: Theory and evidence. Scandinavian Journal of Economics, 107(1), 45-66. http://doi.org/10.1111/j.1467-9442.2005.00394.x 